\title{
Supply Chain Performance of SMEs: The Role of Triple-A Strategy
}

\author{
Baziedy Aditya Darmawan', Rif'atul Laili Maulida² \\ and Mochamad Nasito ${ }^{3}$ \\ 1,2,3 Universitas Islam Indonesia, Yogyakarta, Indonesia
}

baziedy@uii.ac.id

\begin{abstract}
Agility, adaptability, and alignment (henceforth referred as triple-A) are supply chain strategy that supports sustainable competitive advantage. The previous studies found that triple-A is a principle to achieve the superior supply chain performance. However, a study that investigate the triple-A of SME, especially in culinary industry is still limited. This study aims to investigate the effect of triple-A towards SME supply chain performance in culinary industry. Using convenience sampling technique, 98 SMEs were involved in this study. The results of the multiple regression analysis show that the triple-A supply chain strategy has a significant effect on supply chain performance. This finding explain that SME supply chain performance are affected by their ability in managing supply chain strategy that categorized as agility, adaptability, and alignment. This finding gives an empirically supports that agility, adaptability, and alignment are antecedent variables of SME supply chain performance.

Keywords: Triple-A, agility, adaptability, alignment, supply chain, performance.
\end{abstract}

\begin{tabular}{ll}
\hline JEL & $:$ M10 \\
DOI & $: 10.24002 /$ kinerja.v25i1.3588
\end{tabular}

Received : 01/28/2021 Reviewed: 02/03/2021 Final Version: 02/27/2021

\section{INTRODUCTION}

Supply chain is an important process in managing business and build a longterm competitive advantage amid the dynamic business environment. According to Russell and Taylor (2011:8), the supply chain covers all activities related to the flow and transformation of goods and services, from the raw materials into the finished goods which delivered to the end customers. With the continues changes of 
demand, integration and collaboration throughout the whole supply chain are principle (Lambert and Cooper, 2000).

Lee (2004) introduced agility, adaptability, and alignment (henceforth known as triple-A framework) being the key elements in enhancing supply chain performance. Supply chain performance that affected by triple-A supply chain strategy is the key to achieves the competitive advantage (Lee, 2004) in term of cost, quality, delivery, and flexibility (Alfalla-Luque et al., 2018). Hence, the success of organizations in facing environment changes will be depending on how they can adjust the supply chain, that comprise of managing the changes of customer demand, restructure the supply chain, and aligning strategy throughout the supply chain (Lee, 2004).

The previous studies found that triple-A has a relationship with supply chain performance. Whitten et al. (2012) found that triple-A supply chain management is a supply chain management strategy that aimed primarily to improve supply chain performance. Attia (2015) explain that triple-A supply chain can help the organization to achieve the superior supply chain performance.

To the best of our knowledge, the study regarding triple-A supply chain was very limited, especially in developing countries. The previous studies of triple-A supply chain were conducted in developed countries (Lee, 2004; Whitten et al., 2012; Nguyen, 2017; Alfalla-Luque et al., 2018; Marin-Garcia et al., 2018) that has different characteristics with the developing countries (Molla and Licker, 2005). Furthermore, the previous studies were focus on large companies, especially manufacture industry (Lee, 2004; Whitten et al., 2012; Attia, 2015), it means, the results may just be relevant for the large companies but not for the small-medium enterprises (SMEs).

This study attempts to give a contribution by investigating the triple-A supply chain framework and its effect on supply chain performance of SME in culinary industry. With a little attention of researcher, in term of SMEs' supply chain performance, it is necessary to capture how they manage their supply chain. The supply chain of culinary industry itself is unique since there are challenges in managing many varieties of food to guarantee the safety and quality for the final consumers, namely perishability, quality decay, and short shelf life (Bortolini et al., 2019: 305).

\section{LITERATURE REVIEW}

According to Lee (2004), organizations required the triple-A supply chain strategy to achieve competitive advantage. Lee (2004) explain that organizations must be able to response the short-term changes in consumer demand quickly, throughout their supply chain (agility); adapt to the long-term economic and market changes by restructuring their supply chain (adaptability); and able to integrate and coordinate their business processes in order to share the risks, costs and benefits that are obtained by all partners in the supply chain (alignment). Lee (2004) 
concluded that triple-A supply chain strategy will be led organization in achieving superior supply chain performance.

The implementation of the triple-A strategy is certainly having an influence to all entities throughout the supply chain network. According to Whitten et al. (2012) agility, adaptability, and alignment are supply chain strategies that are integrated and coordinated with partners in the supply chain network. Hence, the implementation of triple-A will encourage all entities in the supply chain network to develop adaptive systems to respond the market (demand fluctuation) and economic changes that improve the supply chain performance, and ultimately led the organization to achieve the competitive advantages (Whitten, 2012).

\subsection{Supply Chain Performance}

Supply chain performance is essentials for organizations since its success required a superior performance of supply chain (Rosenzweig et al., 2003) to adapt with the dynamic environment (Vanderhaeghe and de Treville, 2003). In addition, supply chain performance could be affecting the competitive position, hence, managing the supply chain performance has become critical issue (Attia, 2015). Chen and Paulraj (2004) define supply chain performance as the ability to satisfy the end customer, both in terms of quality and cost. In addition, Green and Inman (2005) argued that supply chain performance is related with delivering quality products and services at the right quantity and time to minimize the total cost of products and services to the end customers of the supply chain. From these opinions, it can be concluded that supply chain performance is the ability to deliver quality products to end customers in sufficient quantities and in the right time to ensure their satisfaction.

\subsection{Supply Chain Agility and Supply Chain Performance}

Lee (2004) defines agility as the ability to respond to short-term changes in demand and supply quickly and handle external disturbances with ease. Forsberg and Towers (2007) argue that supply chain agility is essential for the success of all entities in the supply chain network. Furthermore, Baker (2008) also argues that agility combines the ability of all entities in the supply chain to work together in reacting quickly to changes in customer demand.

The ability of all entities in the supply chain network to quickly respond the changes of market demand, required the openness of information sharing. Thomas (2008) argued that sharing information among partners in the supply chain network could support the collaboration which is a key of supply chain's ability to respond market changes. The fluctuating demand is a risk faced by all entities in the supply chain network. According to Tang and Tomlin (2008) the fluctuating customer demand could lead into a risk, that requires supply chain to develop a degree of flexibility in response to these changes. Furthermore, Christopher and Towill (2000) and Wu and Barnes (2012) argued that building a dynamic alliance with different companies is a principal to create an agile supply chain. 
Supply chain agility has an important role that support the organizational performance (Khan et al., 2009; Yusuf et al., 2014). Lee (2004) argues that supply chain performance is depend on the ability to response the short-term changes as the impact of fluctuations in customer demand (agility). Whitten et al. (2012) and Attia (2015) found that agility is a Triple-A dimension that has a positive effect on supply chain performance.

$\mathrm{H} 1$ : The supply chain agility has a positive effect on supply chain performance.

\subsection{Supply Chain Adaptability and Supply Chain Performance}

In an uncertain business environment, the ability of supply chain to adapt with the current circumstances, is something that needs to be achieved. Lee (2004) defines adaptability as the ability to adapt supply chain designs by modifying the supply network in response to structural changes in the market. Lee (2004) argued that adaptability is important in the supply chain because the market will change over a period of time as a result of the changing in product life cycle. In this context, Richey et al. (2006) stated that partners in the supply chain network requires adaptability which allows them to work more efficient.

Uncertainty, in terms of quality, delivery time, and costs are problems that arises when organization try to improve the supply chain adaptability (Newman, 1992). As a result of supply chain adaptability, organizations sense the need of new suppliers in order to develop a new supply base to reduce uncertainty (McCullen et al., 2006). Supply chain adaptability can also be improved through the creation of flexible product designs (McCullen et al., 2006). In this context, the design of a product must be easily adapted from a certain market to another (Whitten et al., 2012). Furthermore, in a continuously shrinking product life cycle and evolving product types (Wang et al., 2008), flexible design, as part of the supply chain's adaptability is essential (Whitten et al., 2012).

According to Stevenson and Spring (2007), adaptability is essential factors that support supply chain performance. Chan et al. (2009) also found that adaptability will enhance the performance of the whole supply chain. Furthermore, Whitten et al. (2012) and Attia (2015) found that adaptability is a Triple-A dimension that has a positive effect on supply chain performance.

H2: The supply chain adaptability has a positive effect on supply chain performance.

\subsection{Supply Chain Alignment and Supply Chain Performance}

Lee (2004) describes alignment in the supply chain as the ability to align the interests of all partners in the supply chain network with the organization's interest. According to Whitten et al. (2012), alignment must be extended beyond the internal functional structure of the organization, to meet the requirement of alignment with external partners in the supply chain network.

From a strategic perspective, business processes in the supply chain, such as purchasing, production, marketing, and logistics must be aligned, both internally and 
externally throughout the supply chain to achieve the ultimate goal of competitive advantage (Bryson, 2004:250). Furthermore, Whitten et al. (2012) and Attia (2015) found that alignment is a Triple-A dimension that has a positive effect on supply chain performance.

H3: The supply chain alignment has a positive effect on supply chain performance.

\section{METHODOLOGY}

This study used a non-probability sampling design and convenience sampling technique. Sekaran and Bougie (2016: 247), stated that convenience sampling is a sampling technique based on the easiness to meet the sample members. This sampling technique was chosen because there are no specific criteria for sampling. The samples chosen were SMEs engaged in the culinary sector, either in the form of restaurants, snack stalls, café, or beverage stalls located in Yogyakarta.

Data were collected using a questionnaire containing items adapted from Whitten et al. (2012). The questionnaire was distributed SMEs which represented by the owner, manager or a person who manages related with supply chain, logistics and operations in each SME, table 1 summarize of respondents' profile. The questionnaire was arranged by using a Likert scale of 1 - 5 (strongly disagree strongly disagree) as a measuring tool for each item. Table 2 summarizes all items (21) used in the questionnaire that consist of 4 items for agility, 5 items for adaptability, 3 items for alignment, and 9 items for supply chain performance. Eventually, this study involved 98 culinary SMEs as the sample to test the effect of triple-A on supply chain performance.

Table 1. The profile of respondents

\begin{tabular}{lr}
\hline Category & Frequency $(\%)$ \\
\hline Role & \\
Owner & 78 \\
Operations manager & 6 \\
Logistics officer & 12 \\
Other & 4 \\
& \\
Sector & \\
Restaurant & 49 \\
Traditional dishes & 12 \\
Snack stall & 21 \\
Beverage stall & 6 \\
Café & 4 \\
Catering service & 2 \\
Pastry & 1 \\
Other & 3 \\
\hline
\end{tabular}


As shown at the table 1, a total of 98 respondents of culinary SMEs had filled out a complete questionnaire. Based on role category, the majority of respondents are representing as the owner of SMEs (78\%), and the rest are logistics officer $(12 \%)$, operations manager $(6 \%)$ and other $(4 \%)$. Furthermore, based on the sector, the majority of respondents are representing culinary SMEs in the form of restaurant $(49 \%)$, and the rest are snack stall $(21 \%)$, traditional dishes $(12 \%)$, beverage stall $(6 \%)$, café $(4 \%)$, catering service $(2 \%)$, pastry $(1 \%)$, and other $(3 \%)$.

Table 2 shows the results of the validity and reliability tests of instruments that measure agility, adaptability, alignment, and supply chain performance variables. The validity test was conducted by using bivariate correlation to determine the correlation of each item with the total score of a construct. Based on the table 2, all items have a significant positive correlation, so it can be concluded that all items in the questionnaire are valid. Reliability test was conducted using Cronbach's Alpha to determine the consistency of the instrument. Garver and Mentzer (1999) recommend a Cronbach's Alpha coefficient of more than 0.70 as the approximate reliability level of an instrument. As shown at table 2, the Cronbach's Alpha coefficient value on each variable is higher than 0.70 , so it can be concluded that the instrument has a good consistency. The values of Cronbach's Alpha are 0.713 (agility), 0.804 (adaptability), 0.863 (alignment), and 0.824 (supply chain performance).

After ensuring the validity and reliability of instruments, hypotheses testing was conducted with a multiple regression analysis, where supply chain performance is the dependent variable, while agility, adaptability, and alignment are independent. In addition, the correlation test was also conducted to determine the relationship between variables.

Table 2. The validity and reliability of instruments

\begin{tabular}{ll}
\hline Variable & Correlation \\
& \\
\hline Agility & 0.696 \\
Establish a good communication with suppliers and consumers & 0.757 \\
Develop a good cooperative relationship with suppliers & 0.722 \\
Have a reliable supplier. & 0.764 \\
Have a good inventory planning in the uncertain circumstances & \\
& \\
Adaptability & 0.713 \\
Monitor the business environment changes to find a new market. & 0.784 \\
Finding new suppliers to adapt to markets changes. & 0.572 \\
Develop products based on consumer needs. & 0.867 \\
Has diverse product variants. & 0.753 \\
Measuring product image compare it with the similar in the market. & 0.763 \\
& \\
Alignment & \\
lnform the products to suppliers and consumers openly. & 0.804 \\
Has a clear rights and obligations with suppliers and consumers? & 0.884 \\
Share the risks, costs and benefits with suppliers and consumers fairly. & 0.904 \\
\hline
\end{tabular}




\begin{tabular}{ll}
\hline Variable & Correlation \\
\hline $\begin{array}{l}\text { Supply Chain Performance } \\
\text { The supply chains are able to deliver products to consumers without defect. }\end{array}$ & 0.648 \\
$\begin{array}{l}\text { The supply chains are to transform raw materials from suppliers into } \\
\text { finished products. }\end{array}$ & 0.619 \\
The supply chains are able to reduce delays, breakdowns, and & 0.598 \\
incompleteness in fulfilling consumer orders. & \\
The supply chains are able to respond and fulfill consumer orders & 0.644 \\
immediately. & 0.768 \\
The supply chains are able to deliver orders to consumers on time. & 0.628 \\
The supply chains are able to fulfill consumer's orders in correct quantity. & 0.687 \\
The supply chains are able to deliver orders with different quantities & \\
according to consumer orders consistently. & 0.700 \\
The supply chains are able to fulfill consumer's orders either in small or & 0.557 \\
large quantities. & 0.824 \\
The supply chain is able to minimize the total cost of production process. & \\
\hline
\end{tabular}

\section{RESULT AND DISCUSSION}

\subsection{Result}

Table 3 shows that all variables have a significant relationship among one another. This explains that the Triple-A dimension (agility, adaptability, and alignment) were related to one another. In addition, these dimensions, also have a significant relationship to supply chain performance, with value of 0,462 (agility), 0,422 (adaptability), and 0,453 (alignment).

Table 3. Correlation among variables

\begin{tabular}{llcccccc}
\hline & Mean & SD & 1 & 2 & 3 & 4 \\
\hline 1 & Supply Chain Performance & 36.99 & 3.957 & 1 & $0.462^{* *}$ & $0.422^{* *}$ & $0.453^{* *}$ \\
2 & Agility & 15.52 & 2.111 & $0.462^{* *}$ & 1 & $0.201^{*}$ & $0.307^{* *}$ \\
3 & Adaptability & 19.23 & 2.555 & $0.422^{* *}$ & $0.201^{*}$ & 1 & $0.273^{* *}$ \\
4 & Alignment & 11.224 & 2.254 & $0.453^{* *}$ & $0.307^{* *}$ & $0.273^{* *}$ & 1 \\
\hline
\end{tabular}

Note: ${ }^{*}$ and ${ }^{* *}$ denote significance level on $5 \%, 1 \%$, respectively.

Table 4 shows that the Adjusted R2 in this model (consisting of agility, adaptability, alignment, and supply chain performance) has a value of 0,374 . It explains that as much as $37,4 \%$ of the variation in supply chain performance can be explained by the triple-A dimension, while the rest is affected by the other factor the not included in this study. The coefficient (estimate) of all independent variables in table 4 are positive. It means that all triple-A dimensions (agility, adaptability, alignment) have a positive effect on supply chain performance. 
Table 4. Multiple regression among variables

\begin{tabular}{ccc}
\hline & \multicolumn{2}{c}{ Supply Chain Performance } \\
\cline { 2 - 3 } Agility & Estimate & $\mathrm{t}$ \\
\cline { 2 - 3 } Adaptability & $0.600^{* *}$ & \\
& $(0.160)$ & 3.763 \\
Alignment & $0.437^{* *}$ & \\
& $(0.130)$ & \\
Adj $\mathrm{R}^{2}$ & $0.488^{* *}$ & \\
$\mathrm{~F}$ & $(0.152)$ & \\
$\mathrm{df}$ & 0.374 & \\
$\mathrm{n}$ & $20.290^{* *}$ & \\
& 97 & \\
& 98 & \\
\end{tabular}

Note: ${ }^{* \star}$ denote significance level on $1 \%$.

As shown at table 4, agility has the biggest effect on supply chain performance with a coefficient value of 0,600 compared to the other independent variables, namely adaptability $(0,437)$ and alignment $(0,488)$. Furthermore, the effect of agility, adaptability, and alignment on supply chain performance is significant at the $p<0,01$ level, hence, all hypotheses in this study $(\mathrm{H} 1, \mathrm{H} 2$, and $\mathrm{H} 3)$ are accepted.

\subsection{Discussion}

The positive and significant effect of agility on supply chain performance means that the overall performance of the supply chain was affected by the ability of the organization to response the short-term changes in market demand and supply promptly, and at the same time, being able to handle the external disruptions (Lee, 2004; Baker, 2008). As proposed in the model adapted from Whitten et al. (2012), the agility was developed through a good communication process between the organization and external parties, namely suppliers and consumers. In addition, supply chain performance can also be supported by agility capabilities by developing good cooperative relationships with suppliers and ensuring that suppliers can be relied on in contingency planning when demand uncertainty occurs. This finding is consistent with (Whitten et al., 2012; Attia, 2015) and support Lee (2004) that propose agility as the element of triple-A in to build a superior supply chain performance.

The positive and significant effect of the adaptability on supply chain performance means that the overall performance of supply chain was also depend on the ability of organization to adapt with the uncertain business environment. This 
finding confirmed that adaptability could be achieved by modifying the supply network in response to the market changes (Lee, 2004). As proposed by Whitten et al. (2012), this adaptability can be developed through monitoring the business environment changes in order to find new market opportunities and at the same time finding new suppliers to adapt to market changes and developed varied products based on consumer needs. This finding is consistent with the triple-A framework proposed by Lee (2004) and also support some previous studies that investigate adaptability and supply chain performance (Stevenson and Spring, 2007; Chan et al., 2009; Whitten et al., 2012; and Attia, 2015).

The positive and significant effect of alignment on supply chain performance means alignment was also essential to achieve the superior supply chain performance. This finding is consistent with Lee (2004) who argued that the ability of the organizations to align their interests with the interests of all partners throughout the supply chain network could led to substantial performance of supply chain. This finding also supports the previous study which found that the alignment of business processes in the supply chain both, internally and externally could contribute in achieving competitive advantage (Bryson, 2004:250) and enhance the overall performance of the supply chain (Lee, 2004; Whitten et al., 2012; Attia, 2015).

\section{CONCLUSION}

Mainly, this study provides scientific contributions in supporting the triple-A theory developed by Lee (2004) which stated that a superior supply chain performance must be achieved with agility, adaptability, and alignment supply chain strategy. This study also supports Whitten et al. (2012) and Attia (2015) in examine the effect of triple-A on the supply chain performance. In fact, to the best of our knowledge, this study is the first that investigate the triple-A on SMEs in culinary industry and resulting the positive and significant effect on their supply chain performance. Moreover, this study proved that the triple-A dimensions (agility, adaptability, and alignment) are the antecedent variables of supply chain performance respectively.

\subsection{Managerial Implication}

This study provides some essentials managerial implication for SME in culinary industry. Based on the findings of this study, the management of SME in culinary industry should consider the triple-A supply chain strategy in improving their supply chain performance as an effort to gain a competitive advantage. Agility in managing the supply chain is a key in establishing a superior supply chain performance, followed by ensuring the alignment of interests among partners throughout the supply chain network, and increasing the adaptability by seeking opportunities in market uncertainty. 


\subsection{Limitation and Future Direction}

This study has some limitation to be considered. First, this study was limited to SMEs engaged in the culinary industry and has a limited number of samples. For this reason, the future study that investigate the triple-A in other industry with larger sample sizes could be considered. Second, this study only focuses on the use of triple-A in measuring supply chain performance. Considering that the coefficient of determination in this study is not large enough to explain supply chain performance, the future study that develops advanced models in measuring supply chain performance is also necessary.

\section{REFERENCE}

Alfalla-Luque, R., Machuca, J. A., and Marin-Garcia, J. A., 2018. Triple-A and competitive advantage in supply chains: Empirical research in developed countries. International Journal of Production Economics, 203, 48-61.

Attia, A., 2015. Testing the effect of marketing strategy alignment and triple-A supply chain on performance in Egypt. EuroMed Journal of Business, 10(2), 163-180.

Baker, P., 2008. The design and operation of distribution centres within agile supply chains. International Journal of Production Economics, 111(1), 27-41.

Bortolini, M., Accorsi, R., Gamberi, M., and Pilati, F., 2019. A model to enhance the penetration of the renewables to power multistage food supply chains. In Sustainable Food Supply Chains, 305-315. Academic Press.

Bryson, J.M., 2004. Strategic Planning for Public and Nonprofit Organizations: A Guide to Strengthening and Sustaining Organizational Achievement. $3^{\text {rd }}$ Edition. San Francisco: Jossey-Bass.

Chan, H.K., Wang, W.Y.C., Luong, L.H.S. and Chan, F.T.S., 2009. Flexibility and adaptability in supply chains: a lesson learnt from a practitioner. Supply Chain Management: An International Journal, 14(6), 407-410.

Chen, I.J. and Paulraj, A., 2004. Towards a theory of supply chain management: the constructs and measurements. Journal of Operations Management, 22(2), 119-150.

Christopher, M. and Towill, D.R., 2000. Supply chain migration from lean and functional to agile and customized. Supply Chain Management: An International Journal, 5(4), 206-213.

Forsberg, J. and Towers, N., 2007. Creating agile supply networks in the fashion industry. The Journal of the Textile Institute, 98(4), 377-386. 
Garver, M.S. and Mentzer, J.T., 1999. Logistics research methods: employing structural equation modeling to test for construct validity. Journal of Business Logistics, 20(1), 33-57.

Green, K.W. Jr and Inman, R.A., 2005. Using a just-in-time selling strategy to strengthen supply chain linkages. International Journal of Production Research, 43(16), 3437-3453.

Khan K, A., Bakkappa, B., Metri, B. A., and Sahay, B. S., 2009. Impact of agile supply chains' delivery practices on firms' performance: cluster analysis and validation. Supply Chain Management: An International Journal, 14(1), 41-48.

Lambert, D.M. and Cooper, M.C., 2000. Issues in supply chain management. Industrial Marketing Management, 29(1), 65-83.

Marin-Garcia, J. A., Alfalla-Luque, R., and Machuca, J. A., 2018. A Triple-A supply chain measurement model: validation and analysis. International Journal of Physical Distribution \& Logistics Management, 48(10), 976-994.

McCullen, P., Saw, R., Christopher, M. and Towill, D., 2006. The F1 supply chain: adapting the car to the circuit - the supply chain to the market. Supply Chain Forum: International Journal, 7(1), 14-23.

Molla, A, and Licker, P. S., 2005. eCommerce adoption in developing countries: a model and instrument. Information \& Management, 42(6), 877-899.

Newman, W.H., 1992. Focused joint ventures' in transforming economies. Academy of Management Executive, 6(1), 67-75.

Nguyen, T. T. H., 2017. Wal-Mart's successfully integrated supply chain and the necessity of establishing the Triple-A supply chain in the 21st century. Journal of Economics \& Management, 29(3), 102-117.

Lee, H.L., 2004. The triple-A supply chain. Harvard Business Review, 82(10), 102112.

Rosenzweig, E.G., Roth, A.V. and Dean, J.W. Jr., 2003. The influence of an integration strategy on competitive capabilities and business performance: an exploratory study of consumer products manufacturers. Journal of Operations Management, 21(4), 437-456.

Richey, R.G., Tokman, M. and Wheeler, A.R., 2006. A supply chain manager selection methodology: empirical test and suggested applications. Journal of Business Logistics, 27(2), 163-190. 
Russel, R.S. and Taylor, B.W., 2011. Operations and Supply Chain Management. $7^{\text {th }}$ ed. Danvers: John Wiley and Sons.

Sekaran, U. and Bougie, R., 2016. Research Methods for Business. $7^{\text {th }}$ ed. Chichester: John Wiley \& Sons.

Stevenson, M. and Spring, M., 2007. Flexibility from a supply chain perspective: definition and review. International Journal of Operations \& Production Management, 27(7), 685-713.

Tang, C. and Tomlin, B., 2008. The power of flexibility for mitigating supply chain risks. International Journal of Production Economics, 116(1), $12-27$.

Thomas, R., 2008. Exploring relational aspects of time-based competition. International Journal of Physical Distribution \& Logistics Management, 38(7), 540550 .

Vanderhaeghe, A. and de Treville, S, 2003. How to fail at flexibility. Supply Chain Forum: An International Journal, 4(1), 64-73.

Wang, L., Keshavarzmanesh, S. and Feng, H-Y., 2008. Design of adaptive function blocks for dynamic assembly planning and control. Journal of Manufacturing Systems, 27(1), 45-51.

Whitten, G.D, Green Jr, K.W., and Zelbst, P.J., 2012. Triple-A Supply Chain Performance. International Journal of Operations \& Production Management, 32(1), 28-48.

Wu, C. and Barnes, D.A., 2012. Dynamic feedback model for partner selection in agile supply chains. International J. Operations and Production Management, 32(1), 79-103.

Yusuf, Y. Y., Gunasekaran, A., Musa, A., Dauda, M., El-Berishy, N. M., and Cang, S., 2014. A relational study of supply chain agility, competitiveness and business performance in the oil and gas industry. International Journal of Production Economics, 147, 531-543. 